\title{
COMPOSIÇÃO QUÍMICA E COMPOSTOS FENÓLICOS EM ARACHIS PINTOI 'BELMONTE'
}

\author{
CHEMICAL COMPOSITION AND PHENOL CONTENTS \\ OF ARACHIS PINTOI 'BELMONTE'
}

\author{
Paulino, V.T. ${ }^{1 A}$, Bueno, M.S..$^{1 B}$ e Abdalla, A.L. ${ }^{2}$ \\ IInstituto de Zootecnia. CPDNAP, IZ/APTA-SAA. Nova Odessa-SP. Brasil. Apaulino@iz.sp.gov.br; \\ Bmsbueno@iz.sp.gov.br \\ ${ }^{2}$ Cena-Centro de Energia Nuclear na Agricultura. Universidade de São Paulo. Piracicaba-SP. Brasil.
}

\section{Palavras chave adicionais}

Fibra. Leguminosa. Proteína bruta. Taninos.

\section{RESUMO}

Foi estudado o efeito de idades de crescimento (64, 82, 112 e 142 dias) sobre a composição do amendoim forrageiro (Arachis pintoi 'Belmonte') em un delineamento de blocos ao acaso com 4 repetições. Os teores de proteína bruta diminuíram de maneira linear $\left(R^{2}=0,93\right)$ com o avanço da idade, oscilando de 23,55 para $19,1 \%$, com idades de 64 a 142 dias. Houve aumento lineal $(p<0,05)$ nos teores de FDA e FDN e celulose. Não houve influência das idades de corte nos valores médios de taninos totais $(20,2)$, fenóis totais $(31,8)$ e taninos condensados $(15,8)$ em equivalente- $\mathrm{g} / \mathrm{kg}$ de matéria seca. Os teores de PB, mesmo nas idades mais avançadas foram elevados, e os de fibra adequados. A composição de taninos não sofreu efeito da idade, e foram aceitáveis os valores para os fatores antinutricionais.

\section{SUMMARY}

The composition of perennial forage peanut (Arachis pintoi 'Belmonte') was evaluated at different ages (64, 82, 112 and 142 days) of forage harvesting in a complete randomized blocks design with 4 replications. There was a linear decrease $\left(R^{2}=0.91\right)$ of crude protein levels from 23.55 to $19.1 \%$, at 64 and 142 days respectively. There were linear increases for neutral and acid detergent fibers and cellulose levels with increase of harvest age. No differences were observed in total tannin (20.2), total phenol (31.8) and condensed tannins (15.7) in equivalent $\mathrm{g} / \mathrm{kg} \mathrm{DM}$ with increase in age. Perennial peanut has high

\author{
Additional KEYWORDS \\ Crude protein. Fiber. Legume. Tannins.
}

crude protein level, and adequate fiber content, as well. The tannins contents were not modified by age and anti-nutritional factors presented acceptable levels.

\section{INTRODUÇÃO}

O amendoim forrageiro (Arachis pintoi 'Belmonte') é um forragem com bom valor nutritivo e boa produção e pode ser utilizada em pastejo direto, consorciado com gramíneas, ou cortado e fornecido no cocho. As leguminosas podem apresentar em sua composição compostos fenólicos (taninos, fenóis...) que em teores elevados atuam como fatores antinutricionais para os ruminantes (Godoy, 2007). Os taninos de algumas plantas podem produzir efeitos benéficos quando utilizados em quantidades de 20-40 g/kg MS na dieta (Hove et al., 2001). Concentrações de 5 a $10 \%$ da MS reduzem o consumo e a digestibilidade da forragem, sendo prejudiciais à nutrição animal (Min et al., 2003). Em quantidades moderadas, podem melhorar o aproveitamento da proteína dietética e diminuir o parasitismo por helmintos. Objetivou-se evaluar à composição química-bromatológica e taninos de Arachis pintoi 'Belmonte' em função de diferentes idades de crescimento da rebrota. 


\section{PAULINO, BUENO E ABDALLA}

\section{MATERIALE MÉTODOS}

$\mathrm{O}$ amendoim forrageiro (Arachis pintoi 'Belmonte') foi cultivada (de agosto de 2007 a março de 2008) no Instituto de Zootecnia, em Nova Odessa, São Paulo, Brasil, situado a 528 m de altitude, $22^{\circ} 46^{\prime} 40^{\prime \prime}$ latitude Sul e $47^{\circ} 17^{\prime} 45^{\prime \prime}$ longitude Oeste.

Esta forrageira foi estabelecida por mudas plantadas com um espaçamento de 0,40 m, cultivada em um solo Argissolo Vermelho-Amarelo, o qual foi amostrado de 0 $20 \mathrm{~cm}$ de profundidade e apresentou a seguinte composição química: $\mathrm{pH}=3,7$; M.O. $=28 \mathrm{~g} / \mathrm{dm}^{3} ; \mathrm{Ca}+\mathrm{Mg}=2 \mathrm{mmolc} / \mathrm{dm}^{3} ; \mathrm{K}=$ $2,6 \mathrm{mmolc} / \mathrm{dm}^{3}, \mathrm{P}=5 \mathrm{mg} / \mathrm{dm}^{3} ; \mathrm{Al}=16$ mmolc/ $\mathrm{dm}^{3}$ e $\mathrm{V}=6 \%$. Com o intuito de elevar o índice de saturação por bases a $60 \%$ foram utilizadas $4,5 \mathrm{t} / \mathrm{ha}$ de calcário dolomítico (26,6 \% de $\mathrm{CaO}$ e $19,1 \%$ de $\mathrm{MgO}$ e poder relativo de neutralização total-PRNT $=90 \%$ ) em cobertura em agosto de 2007. Em 10 de outubro de 2007 foi realizado um corte de uniformização à altura de $5 \mathrm{~cm}$, e aplicação superficial de $80 \mathrm{~kg} \mathrm{P}_{2} \mathrm{O}_{5} /$ ha (superfosfato simples) e $90 \mathrm{~kg}$ de $\mathrm{K}_{2} \mathrm{O} / \mathrm{ha}$ (cloreto de potássio). Cada unidade experimental constou de parcelas de 4,10 x 3,50 m. No período experimental a precipitação foi de 740,6 mm, cuja distribuição mensal é apresentada na figura $\mathbf{1}$.

Foram coletas amostras em cinco pontos por parcela. Os cortes realizados à altura de $5 \mathrm{~cm}$ do nível do solo, com idades de crescimento de 64, 82, 112 e 142 dias. Os tratamentos foram dispostos em um delineamento experimental de blocos ao acaso com 4 repetições. As amostras foram secas em estufa à $40{ }^{\circ} \mathrm{C}$, com circulação de ar forçada até peso constante e moídas em moinho do tipo Wiley, peneira de $1 \mathrm{~mm}$ para análises químicas e em peneira de $0,25 \mathrm{~mm}$ para determinação de compostos fenólicos. Os teores de matéria seca (MS), proteína bruta (PB), fibra em detergente neutro (FDN) e em detergente ácido (FDA) e celulose (CEL) foram analisadas segundo o método de Goering e Van Soest (1970); as concen- trações de fenóis e taninos totais, pelo método de Folin-Ciocalteu e taninos condensados (proantocianidinas, TC) pelo método butanol-HCl (Godoy, 2007). A análise de variância com medidas repetidas no tempo com o Proc Mixed do programa estatístico SAS (SAS, 1999), sendo as médias pelo Lsmeans ajustado pelo teste Tukey (5\%).

\section{RESULTADOSEDISCUSSÃO}

Os rendimentos de matéria seca em função das idades de crescimento foram incrementados com valores de 250, 364, 631 e $762 \mathrm{~kg} / \mathrm{ha}$, com ajuste significativo para a equação de regressão $\left(Y=0,00159 x^{2}+6,26 x\right.$ $-158,15\left(\mathrm{R}^{2}=0,99\right)$.

Os teores de PB, FDN, FDA e CEL do amendoim forrageiro diminuíram significativamente, de forma linear com avanço da idade (figura 2). Os teores de PB oscilaram de 23,55 para $19,1 \%$, com idades de 64 a 142 dias. Com o incremento na produção de matéria seca com a idade e uma redução da relação folha + pecíolo/caule, que explican parcialmente a redução nos teores de PB. Os valores nos intervalos mais tardios demonstram que essa leguminosa apresenta alto nível protéico e uma grande flexibilidade de utilização e, em todas as idades, foram superiores aos obtidos por Godoy (2007). Com a idade, ocorreram incrementos em os componentes da fração fibrosa. Os teores de FDA

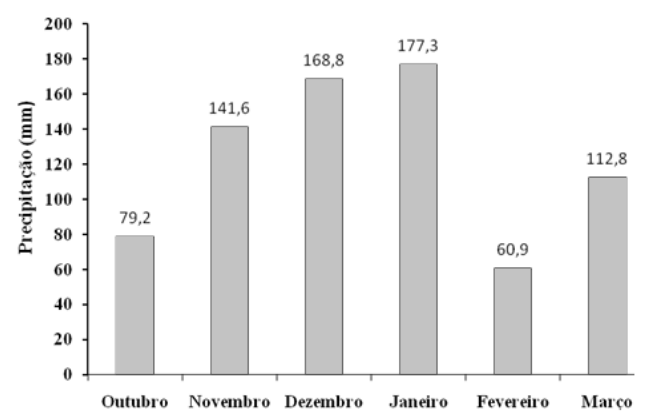

Figura 1. Distribuição da precipitação en 2007-2008. (Distribution of rainfall in 2007-2008). 

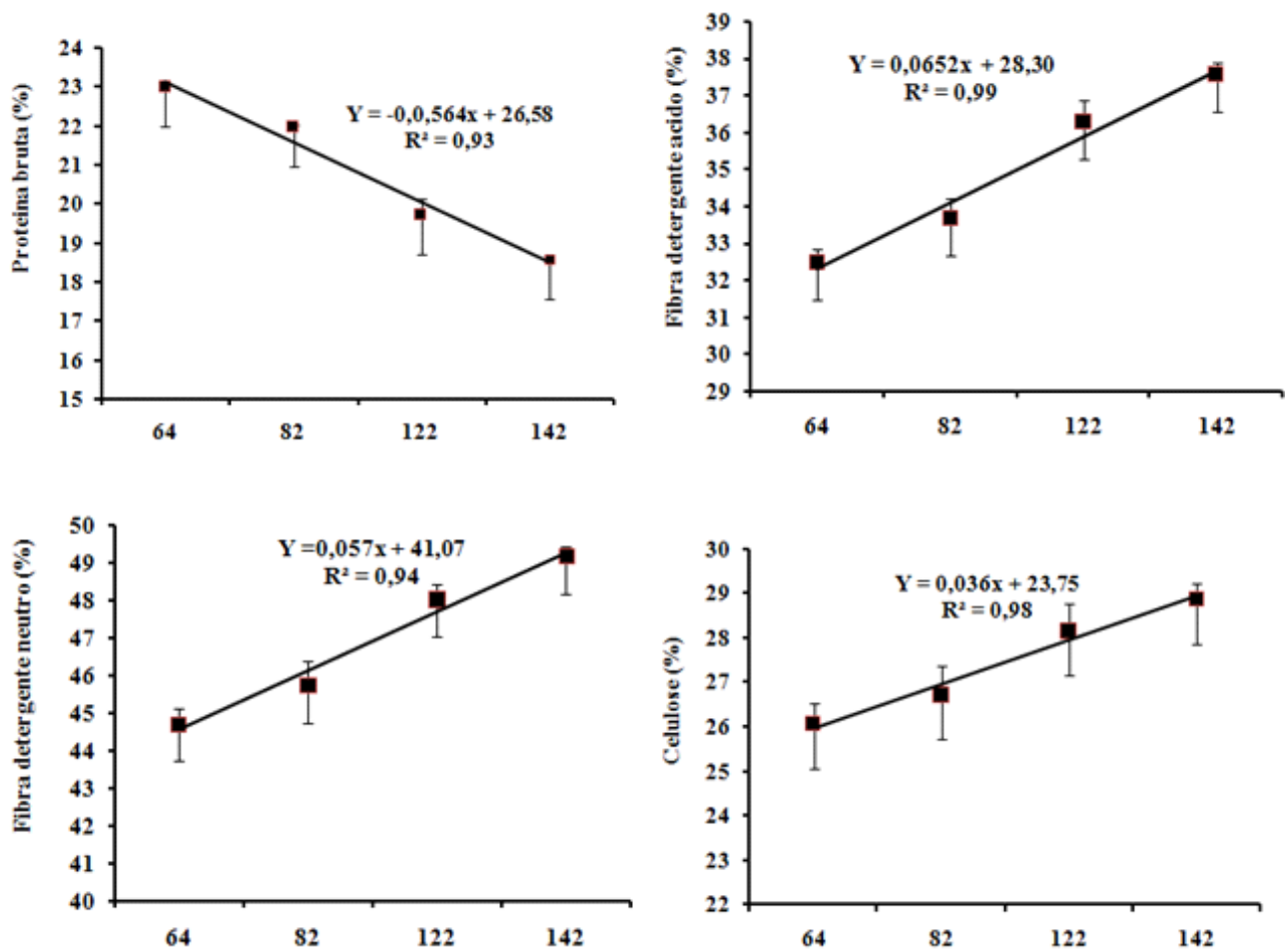

Figura 2. Relação entre as idades de crescimento e teores de proteína bruta, fibra detergente ácido, fibra detergente neutro e celulose do Arachis pintoi. (Relationship between growth age and contents of CP, ADF, NDF and celluloses).

situaram-se entre 33,78 a $37,8 \%$ e os de FDN entre 45,98 a $49,63 \%$, tais valores foram inferiores aos verificados por Godoy (2007).

Não foram observadas diferenças para os teores de taninos e fenóis totais e taninos condensados na parte aérea do amendoim, em função da idade das plantas. Os valores de taninos e fenóis totais situaram-se entre 18,04 a 22,17 e 29,8 a 34,3 (equivalente de ácido tânico $\mathrm{g} / \mathrm{kg} \mathrm{MS}$ ) respectivamente, enquanto os de taninos condensados situaram-se entre 15,2 a 16,7 (equivalente de leucocianidina $\mathrm{g} / \mathrm{kg} \mathrm{MS}$ ). De acordo com a literatura, níveis de taninos acima de $45 \mathrm{~g} / \mathrm{kg}$ MS são tóxicos para os animais com efeitos adversos sobre a palatabilidade ou o desempenho animal (Min et al., 2003), sendo que niveis acima de $90 \mathrm{~g} / \mathrm{kg}$ MS podem levá- los à morte. Alguns autores citam que, para os TC, o limite considerado seguro para os ruminantes encontra-se na faixa de 30 a 40 eq-g leucocianidina/kg de MS (Hove et al., 2001). De acordo com esses autores, nessa faixa, o efeito é benéfico devido à proteção contra a degradação microbiana, podendo aumentar a quantidade de proteína não degradada que chega ao intestino.

Sabe-se que as condições ambientais, tais como temperatura, umidade e fertilidade do solo podem afetar os conteúdos de taninos. Em solos pobres e ácidos muito comuns em regiões tropicais, as leguminosas forrageiras podem apresentam maiores concentrações de taninos (Otero e Hildalgo, 2004). No presente experimento, realizou-se a correção de acidez, adubação fosfatada e 


\section{PAULINO, BUENO E ABDALLA}

potássica, portanto as condições de acidez $\left(\mathrm{pH}_{\mathrm{CaCl} 2}=4,8\right)$ e as concentrações de fósforo disponível $\left(\mathrm{P}=12 \mathrm{mg} / \mathrm{dm}^{3}\right)$ e de potássio $(\mathrm{K}=$ $3,0 \mathrm{mmol} / \mathrm{dm}^{3}$ ) no solo, não foram limitantes ao crescimento desta leguminosa (Paulino et al., 2008), resultando em concentrações moderadas de taninos condensados similares as encontradas por Godoy (2007) de 14,4 em equivalente grama de ácido tânico/kg de matéria seca.

Os teores de fenóis totais foram superiores aos encontrados por Godoy (2007), que obteve 11,1 equivalente grama de ácido tânico/kg de matéria seca.

Teores elevados de taninos condensados na dieta de ruminantes diminuem a digestibilidade aparente de MS e a produção de gás in vitro e podem contribuir para a redução da produção de metano ruminal (Puchala et al., 2005). Diversos trabalhos citados na literatura mostram que quantidades moderadas de taninos condensados (10 a 40 g. $\mathrm{kg}^{-1} \mathrm{MS}$ ) podem prevenir o timpanismo; elevar o fornecimento de proteína by pass (proteína não degradada) para

\section{BIBLIOGRAFIA}

Brandes, D. e Freitas, E.A.G. 1992. Taninos condensados-uma ferramenta para melhorar o desempenho de ruminantes. Agropecuária Catarinense, 5: 44-48.

Hove, L., Topps, J.H., Sibanda, S. and Ndlovu, L.R. 2001. Nutrient intake and utilization by goats fed dried leaves of the shrub legumes Acacia angustissima, Calliandra calothryrsus and Leucaena leucocephala as supplements to native pasture hay. Anim Feed Sci Tech, 91: 95-106.

Godoy, P.B. 2007. Aspectos nutricionais de compostos fenólicos de ovinos alimentados com leguminosas forrageiras. Tese (Doutor em Ciências). Centro de Energia Nuclear na Agricultura. Universidade de São Paulo-CENA. Piracicaba, SP. 94 pp.

Goering, H.K. and Van Soest, P.J. 1970. Forage fiber analysis (apparatus, reagents, procedures, and some applications). Agric. Handbook. ARS, USDA. Washington, DC. 379 pp.

Min, B.R., Barry, T.N., Attwood, G.T. and McNabb, digestão no intestino delgado e melhorar a utilização de aminoácidos essenciais da dieta (Brandes e Freitas, 1992). O baixo nível de taninos condensados poderia explicar as taxas de degradação relativamente lentas da proteína in situ. Por outro lado, a taxa de degradação protéica in situ de espécies de Arachis é bem mais rápida do que a do Desmodium ovalifolium com altos níveis de taninos. Isto sugere que os taninos condensados em espécies de Arachis pode parcialmente proteger a proteína da degradação no rúmen, além disso o amendoim forrageiro apresenta-se também como fonte de N mais fermentescível (produção amônia ruminal).

\section{CONCLUSÕES}

Com a idade, aumentaram os componentes estruturais, e diminuiu os atributos de maior utilização pelos ruminantes de Arachis pintoi. Taninos não foram afetados. Factores antinutricionais e tóxicos são encontradas a níveis aceitáveis.

W.C. 2003. The effect of condensed tannins on the nutrition and health of ruminants fed fresh temperate forages. Anim Feed Sci Technol, 106: 3-19.

Otero, M.J. e Hidalgo, L.G. 2004. Taninos condensados en especies forrajeras de clima templado: efectos sobre la productividad de rumiantes afectados por parasitosis gastrointestinales. Livest Res Rural Develop, 16: 1-9.

Paulino, V.T., Ferrrari Jr., E. e Lucena, M.A.C. 2008. Crescimento, composição química e biológica de Arachis pintoi (Krapov \& Gregory) em função da calagem e da adubação fosfatada para diferentes alturas de corte. In: Zootec 2008. Anais...João Pessoa. ABZ. João Pessoa.

Puchala, R., Min, B.R., Goetsch, A.L. and Sahlu, T. 2005. The effect of a condensed tannincontaining forage on methane emission by goats. J Anim Sci, 83: 182-186.

SAS Institute.1999. User's guide statistics. Release Cary. 863 pp. 